\title{
Aneurysms of the posterior communicating artery and oculomotor paresis
}

\author{
S. R. SONI ${ }^{1}$
}

From the University Hospital of Wales, Cardiff

SYNOPSIS One hundred and seventy-four patients with a posterior communicating aneurysm were seen over a 21 year period. There was a ratio of four females to one male and women were on average five years older. Fifty-nine $(34 \%)$ had an oculomotor paresis. This group had up to four attacks of localized headache, large multiloculated aneurysms, and a greater time lapse from the onset of symptoms to surgery compared with those patients without oculomotor palsy. Delay in treatment allowed further attacks to occur which increased the mortality rate and decreased the chance that the eye would recover. Eighteen people who had had a palsy before craniotomy two to 18 years previously were examined. In four $(22 \%)$ the paralysis had recovered completely, $14(78 \%)$ had greatly reduced oculomotor function, and nine $(50 \%)$ showed aberrant regeneration of the nerve. Nine of 62 patients, seven of whom were seen, developed a palsy after craniotomy and in five the eye had returned to normal.

Enlargement of an aneurysm of the posterior communicating artery may cause an isolated painful third nerve palsy. More commonly the sac ruptures and if the ensuing subarachnoid haemorrhage is associated with such a palsy it should suggest the likely source of bleeding. The effects of carotid artery ligation on aneurysm induced palsies have been described, but little has been written on post-craniotomy results. This study was undertaken to compare the clinical and arteriographic findings in patients with and without a third nerve palsy caused by a posterior communicating aneurysm (PCA), and to assess the degree of recovery after craniotomy of an oculomotor paresis and the incidence of aberrant regeneration of the nerve.

\section{METHODS}

PATIENTS Between 1951 and 1971, 174 patients who were eventually shown to have an aneurysm of the posterior communicating artery were seen at the Cardiff Royal Infirmary (Table 1). Of these, 120 $(69 \%)$ came to the neurosurgical unit from other hospitals and the rest were admitted under the care of the physicians. Those well enough had bilateral carotid angiography, mostly followed in the earlier

\footnotetext{
1 Present address: Morriston Hospital, Swansea, South Wales.
}

TABLE 1

NUMBER OF POSTERIOR COMMUNICATING ANEURYSMS SEEN ANNUALLY IN 21 YEARS

\begin{tabular}{ccr}
\hline & $\begin{array}{c}\text { Patients } \\
\text { (no.) }\end{array}$ & $\begin{array}{c}\text { Average } \\
\text { per year }\end{array}$ \\
\hline $1951-55$ & 22 & $4 \cdot 4$ \\
$1956-60$ & 36 & $7 \cdot 2$ \\
$1961-65$ & 41 & $8 \cdot 2$ \\
$1966-71(6 \mathrm{yr})$ & 75 & $12 \cdot 5$ \\
\hline
\end{tabular}

years by ligation of the common carotid artery, and after about 1958, by direct intracranial attack on the aneurysm.

AGE The age of patients varied from 14 to 81 years with a mean of 50.6 years for patients with a preoperative palsy $(45.3$ years for men and 51.6 for women), and $47 \cdot 5$ years for those without $(44 \cdot 2$ years for men and 48.4 for women) (Fig. 1).

SEX Of the 174 patients, $139(80 \%)$ were female and $35(20 \%)$ male, a ratio of 4 to 1 . Women were on average five years older. The average age of men admitted was 44.5 years \pm SD 10.2 and of women, $49 \cdot 5$ years \pm SD $11 \cdot 8$, the difference being statistically significant $(t=2 \cdot 5, P<0.05)$. 


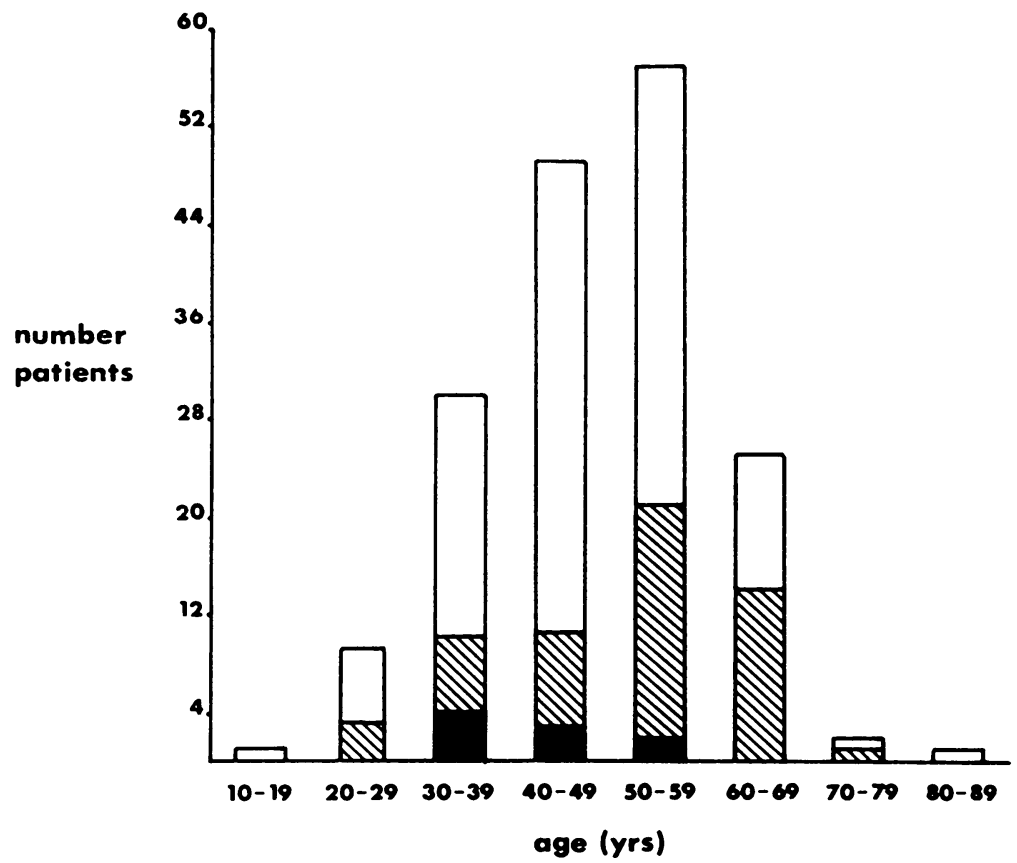

FIG. 1. Age distribution of 174 patients with posterior communicating aneurysms.

$\square$ Total numbers, patients with preoperative 3 rd nerve palsy, postoperative palsy.
TABLE 2

NUMBER OF ATTACKS OF HEADACHE RELATED TO THIRD NERVE PALSY

\begin{tabular}{|c|c|c|c|c|c|c|c|}
\hline \multirow[t]{2}{*}{$\begin{array}{l}\text { Attacks } \\
\text { of pain }\end{array}$} & \multicolumn{2}{|c|}{$\begin{array}{l}\text { Patients } \\
\text { with palsy }\end{array}$} & \multicolumn{2}{|c|}{$\begin{array}{c}\text { Patients } \\
\text { without palsy }\end{array}$} & \multirow[t]{2}{*}{$\begin{array}{c}\text { Total } \\
\text { no. }\end{array}$} & \multirow[t]{2}{*}{ Deaths } & \multirow[t]{2}{*}{$\begin{array}{l}\text { Deaths } \\
\text { per } 100\end{array}$} \\
\hline & (no.) & $(\%)$ & (no.) & $(\%)$ & & & \\
\hline 1 & 20 & 34 & 76 & 66 & 96 & 19 & $19 \cdot 8$ \\
\hline 2 & 25 & 42 & 32 & 28 & 57 & 19 & $33 \cdot 3$ \\
\hline 3 & 11 & 19 & 7 & 6 & 18 & 7 & $38 \cdot 9$ \\
\hline 4 & 3 & 5 & - & - & 3 & 2 & $66 \cdot 7$ \\
\hline Total & 59 & 100 & 115 & 100 & 174 & 47 & $27 \cdot 0$ \\
\hline
\end{tabular}

HEADACHE In all cases there was a recent history before admission of up to three distinct episodes of severe headache. The pain was localized to the eye, orbital region or side of the forehead in $64 \%$ of patients with a third nerve lesion and in only $5 \%$ of those without (a highly significant difference, $\chi^{2}=69$, $\mathrm{n}=1, \mathrm{P}<0.001$ ). Strictly localized pain without meningeal irritation suggested that in six patients the oculomotor palsy preceded a subarachnoid haemorrhage, and in a further three cases no bleeding occurred at all.

Twenty patients with a palsy and 76 without had only one attack of pain (Table 2), but patients with a

\section{TABLE 3}

NUMBER OF ATTACKS OF HEADACHE AND TIMES ASSOCIATED WITH LOSS OF CONSCIOUSNESS

\begin{tabular}{|c|c|c|c|c|c|c|}
\hline \multirow{2}{*}{$\begin{array}{l}\text { Attacks } \\
\text { of pain }\end{array}$} & \multicolumn{3}{|c|}{ Patients with palsy } & \multicolumn{3}{|c|}{ Patients without palsy } \\
\hline & (no.) & $\begin{array}{c}\text { Uncon. } \\
\text { (no.) }\end{array}$ & $\begin{array}{c}\text { Uncon. } \\
(\%)\end{array}$ & (no.) & $\begin{array}{c}\text { Uncon. } \\
\text { (no.) }\end{array}$ & $\begin{array}{c}\text { Uncon. } \\
(\%)\end{array}$ \\
\hline 1 & 59 & 5 & $8 \cdot 5$ & 115 & 56 & 48.7 \\
\hline 2 & 39 & 17 & 43.6 & 39 & 28 & 71.8 \\
\hline 3 & 14 & 12 & $85 \cdot 7$ & 7 & 4 & $57 \cdot 1$ \\
\hline 4 & 3 & 3 & $100 \cdot 0$ & - & - & - \\
\hline
\end{tabular}

palsy irrespective of age had a significantly greater number of attacks than those without $\left(\chi^{2}=5 \cdot 5, \mathrm{n}=1\right.$, $P<0.02)$. The mortality altered significantly with each attack, rising from 19.8 per 100 for patients who had one, to 66.7 per 100 for those having four attacks $\left(\chi^{2}=6.4, \mathrm{n}=2,0.05, \mathrm{P}<0.02\right)$.

The oculomotor palsy followed the first attack of pain in 34 patients, the second in 23 , and the third in two. It was complete immediately in 12 cases and within 24 hours in 15 others. By the end of a week a further 12 palsies had become complete, by the second week one, and by the third six, but five took longer than three weeks and eight remained incomplete.

The first attack of pain was associated with loss of 


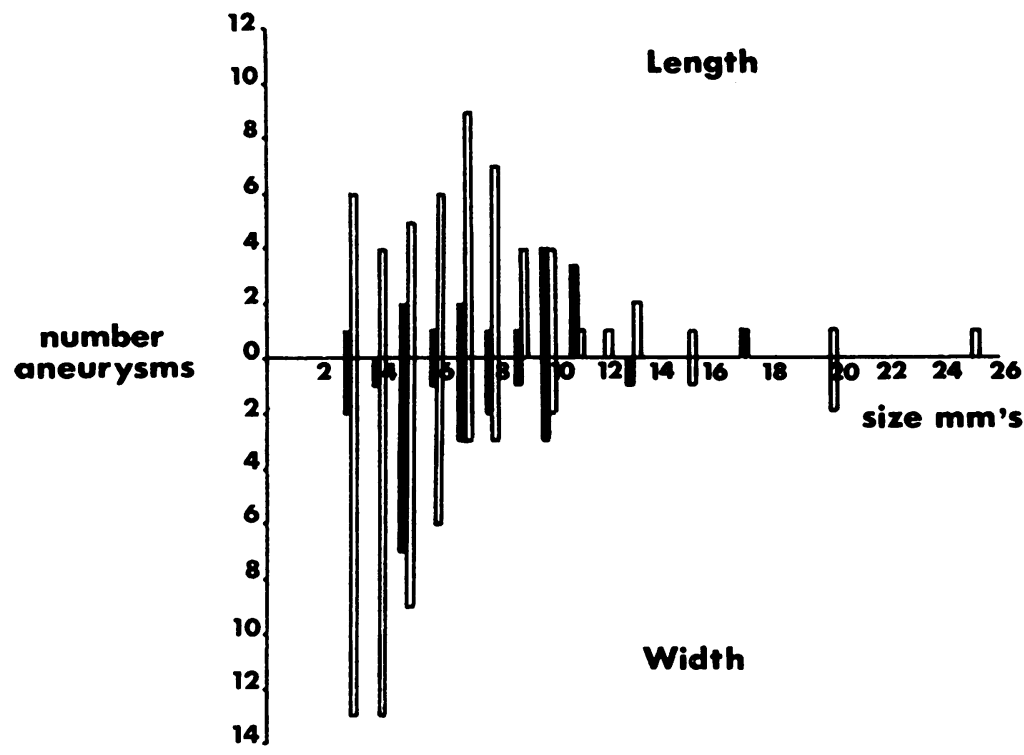

FIG. 2. Size on angiography of 74 posterior communicating aneurysms. $\square$ No palsy (52 patients), with palsy (22 patients).

TABLE 4

NEUROLOGICAL PICTURE OF ALL CASES ON ADMISSION TO THE CARDIFF ROYAL INFIRMARY, AND ASSOCIATED MORTALITY RATES

\begin{tabular}{|c|c|c|c|c|c|c|c|c|}
\hline \multirow[t]{3}{*}{ Neurological picture } & \multicolumn{4}{|c|}{ Patients with palsy } & \multicolumn{4}{|c|}{ Patients without palsy } \\
\hline & \multirow[t]{2}{*}{ (no.) } & \multirow[t]{2}{*}{$(\%)$} & \multicolumn{2}{|c|}{ Deaths } & \multirow[t]{2}{*}{ (no.) } & \multirow[t]{2}{*}{$(\%)$} & \multicolumn{2}{|c|}{ Deaths } \\
\hline & & & (no.) & (rate/100) & & & (no.) & (rate/100) \\
\hline No (other) neurological signs & 31 & $52 \cdot 5$ & 7 & $22 \cdot 6$ & 44 & $38 \cdot 3$ & 3 & $6 \cdot 8$ \\
\hline Drowsy only & 13 & 22 & 5 & $38 \cdot 5$ & 31 & 27 & 11 & $35 \cdot 5$ \\
\hline Hemiparesis only & 3 & $5 \cdot 1$ & - & - & 9 & $7 \cdot 8$ & 1 & $11 \cdot 1$ \\
\hline Drowsy + hemiparesis & 8 & 13.6 & 4 & 50 & 15 & 13 & 3 & $20 \cdot 0$ \\
\hline Drowsy + hemiplegia & 1 & $1 \cdot 7$ & - & - & 3 & $2 \cdot 6$ & 1 & $33 \cdot 3$ \\
\hline Unconscious only & 一 & - & 一 & 一 & 7 & $6 \cdot 1$ & 7 & $100 \cdot 0$ \\
\hline Unconscious + hemiparesis & 2 & 3.4 & 1 & 50 & 3 & $2 \cdot 6$ & 1 & $33 \cdot 3$ \\
\hline Unconscious + hemiplegia & 1 & $1 \cdot 7$ & 1 & $100 \cdot 0$ & 3 & $2 \cdot 6$ & 2 & $66 \cdot 7$ \\
\hline Total & 59 & $100 \cdot 0$ & 18 & $30 \cdot 5$ & 115 & $100 \cdot 0$ & 29 & $25 \cdot 2$ \\
\hline
\end{tabular}

consciousness in 56 patients without a palsy and in only five with palsy. Those who had several episodes of pain were more likely to be rendered unconscious during later attacks (Table 3), and this increased significantly the mortality risk. Patients who were never unconscious had a death rate of 13.5 per 100 and those who were, one or more times, a rate of 37 per $100\left(\chi^{2}=10 \cdot 7, \mathrm{n}=1, \mathrm{P}<0 \cdot 001\right)$. Fourteen patients with a palsy (three with their fourth attack), and nine without, had a coma with headache after admission to the Infirmary.

Eleven patients $(19 \%)$ with a palsy and $68(59 \%)$ without were admitted to the Infirmary within seven days of the onset of the first attack of pain, while 21 patients $(36 \%)$ with and $16(14 \%)$ without palsy were not admitted for over four weeks. There was then an average wait of four days for angiography, of 8.9 days for surgery, and a total stay in the Infirmary of 27.9 days for those who survived. There was no significant difference in these average times for the palsied or the non-palsied groups, and the delay between the first attack of pain and surgery was significantly greater for those people with a palsy than for those without $(t=3.07, P<0.01)$. For all 
TABLE 5

LOCULI OF SAC ON ANGIOGRAPHY

\begin{tabular}{|c|c|c|c|c|}
\hline \multirow[t]{2}{*}{ Loculi } & \multicolumn{2}{|c|}{$\begin{array}{c}\text { Patients } \\
\text { with palsy }\end{array}$} & \multicolumn{2}{|c|}{$\begin{array}{c}\text { Patients } \\
\text { without palsy }\end{array}$} \\
\hline & (no.) & $(\%)$ & (no.) & $(\%)$ \\
\hline 1 & 12 & 34 & 60 & 72 \\
\hline 2 & 18 & 51 & 15 & 18 \\
\hline 3 & 5 & 14 & 8 & 10 \\
\hline Total & 35 & 99 & 83 & 100 \\
\hline
\end{tabular}

TABLE 6

SIDE OF POSTERIOR COMMUNICATING ANEURYSM

\begin{tabular}{llllr}
\hline & Left & Right & Bilat. & Total \\
\hline With palsy & 19 & 38 & 2 & 59 \\
Without palsy & 44 & 64 & 7 & 115 \\
\hline Total & $63(36 \%)$ & $102(59 \%)$ & $9(5 \%)$ & 174 \\
\hline
\end{tabular}

patients there was an average of 17 days between the first and second attacks, 13 days between second and third, and eight days between third and fourth attacks.

CLINICAL PICTURE The patients' neurological state on admission to the Infirmary and the death rates there are shown in Table 4. The mortality is higher, but not significantly so, in patients who had a subarachnoid haemorrhage and a palsy (rate of 30.5 per 100) than for those with subarachnoid haemorrhage alone $(25.2$ per 100$)$, and is similar $(33$ per 100$)$ in those in whom the palsy preceded or was not associated with subarachnoid haemorrhage. In the non-palsied group, there was a significantly higher death rate for those with neurological signs than those without $\left(\chi^{2}=11 \cdot 3, \mathrm{n}=1, \mathrm{P}<0 \cdot 001\right)$.

ANGIOGRAPHY The aneurysm was measured in 47 sets of available film. In 27 others where the radiographs had been destroyed the measurements had been reported by the radiologist. Thus the size of the aneurysm is known in only $74(42 \%)$ of the patients but it is reasonable to take it as a representative

FOLLOW-UP OF THIRD NERVE PALSIES AFTER CRANIOTOMY

\begin{tabular}{|c|c|c|c|c|c|c|c|c|c|c|c|}
\hline \multirow{2}{*}{$\begin{array}{l}\text { Patient } \\
\text { no. }\end{array}$} & \multirow[t]{2}{*}{ Sex } & \multirow{2}{*}{$\begin{array}{c}\text { Age at } \\
\text { operation } \\
(y r)\end{array}$} & \multirow{2}{*}{$\begin{array}{c}\text { Follow- } \\
u p \\
(y r)\end{array}$} & \multirow{2}{*}{$\begin{array}{c}\text { Time from } \\
\text { onset palsy } \\
\text { to surgery } \\
\text { (days) }\end{array}$} & \multicolumn{3}{|c|}{ Residual signs } & \multicolumn{3}{|c|}{ Abnormal regeneration } & \multirow[t]{2}{*}{ Symptoms } \\
\hline & & & & & Ptosis & $\begin{array}{c}\text { Abnormal } \\
\text { pupil } \\
\text { size }\end{array}$ & $\begin{array}{c}\text { Restricted } \\
\text { globe } \\
\text { movements }\end{array}$ & $\begin{array}{c}\text { Mass } \\
\text { contrac- } \\
\text { tion }\end{array}$ & $\begin{array}{c}\text { Pseudo- } \\
\text { Graefe }\end{array}$ & $\begin{array}{c}\text { Abnormal } \\
\text { lid } \\
\text { movements }\end{array}$ & \\
\hline 1 & $\mathbf{F}$ & 57 & 4 & 2 & - & - & - & - & - & - & - \\
\hline 2 & $\mathbf{F}$ & 33 & 12 & 3 & - & - & - & - & - & - & - \\
\hline 3 & $\mathbf{M}$ & 39 & 3 & 4 & - & - & - & - & - & - & - \\
\hline 4 & $\mathbf{F}$ & 53 & 6 & 9 & - & - & - & - & - & - & - \\
\hline 5 & $\mathbf{F}$ & 37 & 3 & 4 & - & + & + & - & - & - & + \\
\hline 6 & $\mathbf{F}$ & 46 & 2 & 8 & + & + & + & - & - & - & + \\
\hline 7 & $\mathrm{~F}$ & 25 & 2 & 11 & - & - & + & - & - & - & + \\
\hline 8 & $\mathbf{F}$ & 54 & 14 & 6 & - & + & + & + & - & - & + \\
\hline 9 & $\mathbf{M}$ & 44 & 14 & 10 & - & - & ++ & + & - & - & + \\
\hline 10 & $\mathbf{F}$ & 50 & 10 & 18 & - & ++ & + & ++ & - & - & + \\
\hline 11 & $\mathbf{F}$ & 34 & 6 & 10 & + & ++ & ++ & ++ & ++ & + & + \\
\hline 12 & $\mathbf{M}$ & 41 & 13 & 14 & + & ++ & + & ++ & + & + & + \\
\hline 13 & $\mathbf{F}$ & 30 & 18 & 26 & + & ++ & ++ & + & - & - & + \\
\hline 14 & $\mathbf{F}$ & 63 & 9 & 28 & - & ++ & ++ & + & - & - & + \\
\hline 15 & $\mathbf{M}$ & 51 & 8 & 42 & - & ++ & ++ & + & - & + & + \\
\hline 16 & $\mathbf{F}$ & 61 & 3 & 60 & + & + & ++ & - & - & - & + \\
\hline 17 & $\mathbf{F}$ & 65 & 3 & 16 & + & ++ & ++ & - & - & - & ++ \\
\hline 18 & $\mathbf{F}$ & 55 & 4 & 42 & + & ++ & ++ & ++ & + & - & ++ \\
\hline 19 & $\mathbf{M}$ & 32 & 2 & Post op. & - & - & - & - & - & - & - \\
\hline 20 & $\mathbf{M}$ & 34 & 5 & Post op. & - & - & - & - & - & - & - \\
\hline 21 & $\mathbf{F}$ & 47 & 5 & Post op. & - & - & - & - & - & - & - \\
\hline 22 & $\mathbf{F}$ & 40 & 6 & Post op. & - & - & - & - & - & - & - \\
\hline 23 & $\mathbf{M}$ & 44 & 4 & Post op. & - & - & - & - & - & - & - \\
\hline 24 & $\mathbf{M}$ & 32 & 3 & Post op. & - & - & + & - & - & - & - \\
\hline 25 & $\mathbf{F}$ & 56 & 12 & Post op. & - & + & ++ & + & - & - & + \\
\hline
\end{tabular}

$-=$ Nil; $+=$ slight $;++=$ gross.

TABLE 7 
sample because the palsy groups occur in similar proportions and age distribution. Fifty per cent of patients with a palsy had aneurysms greater than $11 \mathrm{~mm}$ in length or width, while only $15 \%$ of the others had aneurysm of this size (Fig. 2). On these data the difference is significant $\left(\chi^{2}=9 \cdot 9, \mathrm{n}=2\right.$, $P<0.01)$.

The number of loculi of the sac was given in 71 reports, so this was known in 118 cases (Table 5). Patients with a palsy had aneurysms with significantly more loculi than those without $\left(\chi^{2}=16 \cdot 1\right.$, $\mathrm{n}=2, \mathrm{P}<0.01$ ), but there was no significant correlation of the number of loculi with age, or with the number of attacks of pain.

Nine $(5 \%)$ of the aneurysms were bilateral, $36 \%$ left, and $59 \%$ right sided (Table 6 ). However, in those under 55 years of age, $31 \%$ were left sided and $69 \%$ on the right, while over 55 years, $55 \%$ were left and $45 \%$ right sided. This is a significant difference $\left(\chi^{2}=8.5, \mathrm{n}=1, \mathrm{P}=0.003\right)$, and suggests a changeover with age. At all ages mortality was unaffected by the side involved.

Of the 59 patients with a palsy, six died before treatment, three were discharged without operation, and 13 had a carotid ligation. Thirty-seven underwent a craniotomy and 11 of these died within a few weeks, leaving a possible 26 for follow up. Five of them had died of unrelated causes, two were living abroad, and one was untraced.

Of 63 patients without a palsy who underwent a craniotomy, nine patients (five women and four men) who had small aneurysms which ruptured during operation developed a palsy which was noticed immediately after operation. One died within a few days of operation and another four years later.

FOLLOW-UP Twenty-five patients with a follow-up time of 2 to 18 years were seen personally and had a full orthoptic examination (Table 7). Of the 18 people who had a preoperative palsy, only four had fully recovered; the palsy had been present for less than 10 days before operation and recovery, which started with lessening ptosis, had begun within a few weeks. In the 14 other patients a preoperative palsy had been present for longer than 10 days and first signs of recovery were delayed for several weeks or months. Of these people six had slight and eight gross residual defects, but only two had troublesome symptoms. Twelve of them had occasional diplopia, and three had developed compensatory head tilts.

Aberrant regeneration was obvious in nine of this group, all of whom had their operation four or more years earlier. All showed mass contraction in which the eye adducted on attempted elevation, three showed the pseudo-Graefe sign, and three had other abnormal lid movements, but in no case was an Argyll Robertson reaction found.

Of the seven patients seen who developed a palsy after craniotomy, recovery had started within a few days of operation and in five it was complete within a year. One patient had slightly restricted elevation of the eye, and one, who had occasional symptoms, had gross residual defects and signs of aberrant regeneration.

\section{DISCUSSION}

Aneurysms of the actual posterior communicating artery are rare (Alpers and Schlezinger, 1949; Madow and Alpers, 1953). However, the term includes those aneurysms which arise from the carotid artery at or near its junction with the posterior communicating artery (Dandy, 1944), and it has long been known that they can cause an oculomotor paralysis (France, 1846; Hutchinson, 1875; Beadles, 1907; Symonds, 1923) (Fig. $3)$. The $34 \%$ incidence of palsies in this series compares with the $36 \%$ of Paterson (1968)

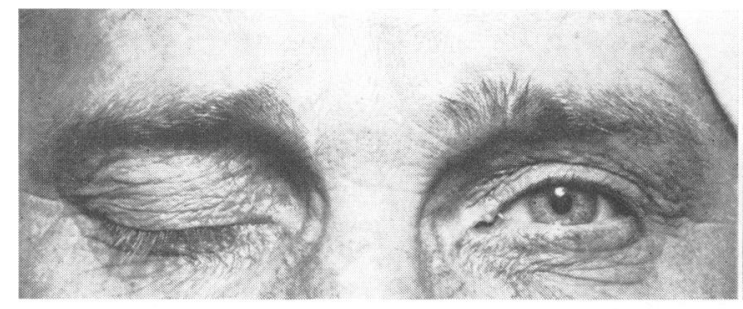

(a)

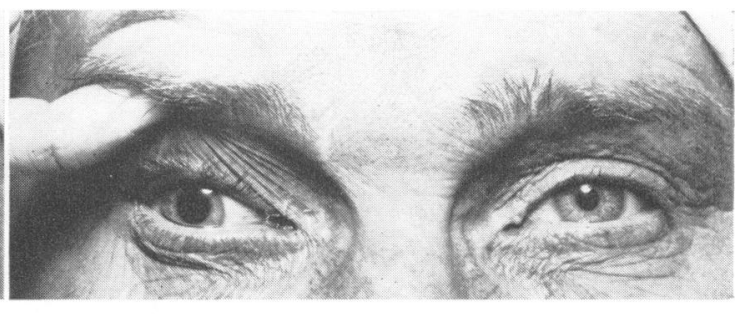

(b)

FIG. 3. Patient 12. (a) Preoperative picture, (r) third nerve palsy, complete ptosis. (b) When the paralysed lid is raised the eye is deviated laterally, and the pupil is dilated. 


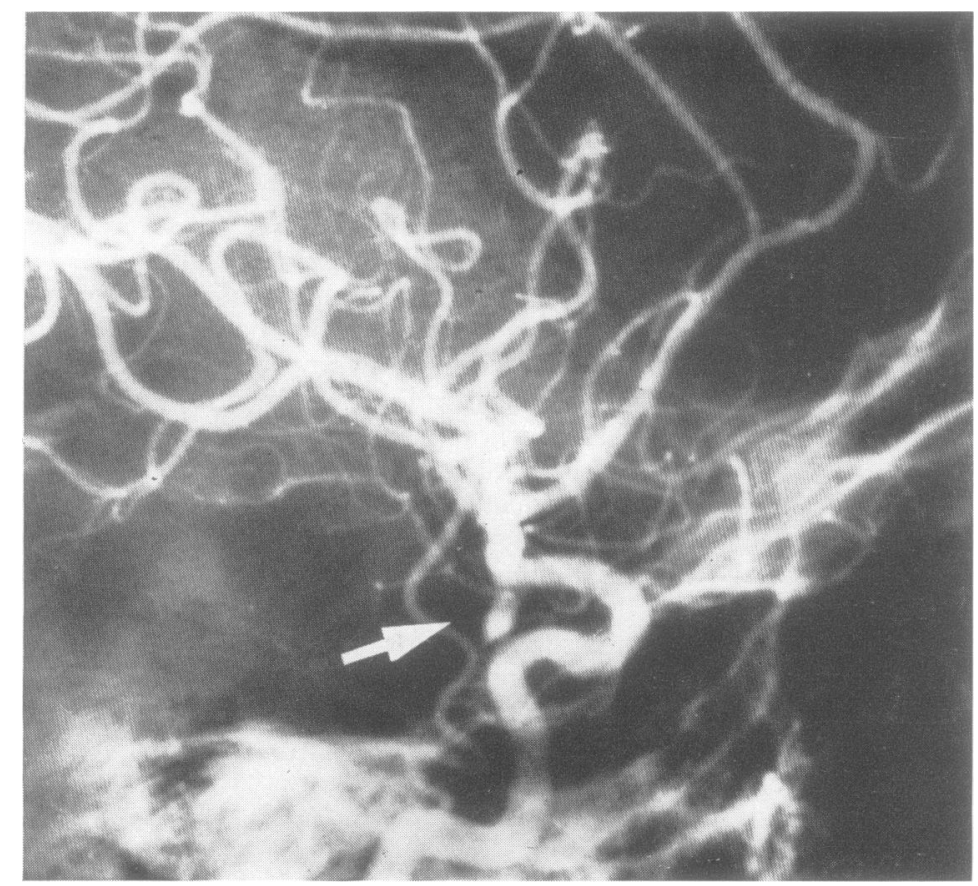

FIG. 4. Right carotid angiogram (lateral view). Small non-loculated posterior communicating aneurysm (arrowed). Not associated with a third nerve palsy.

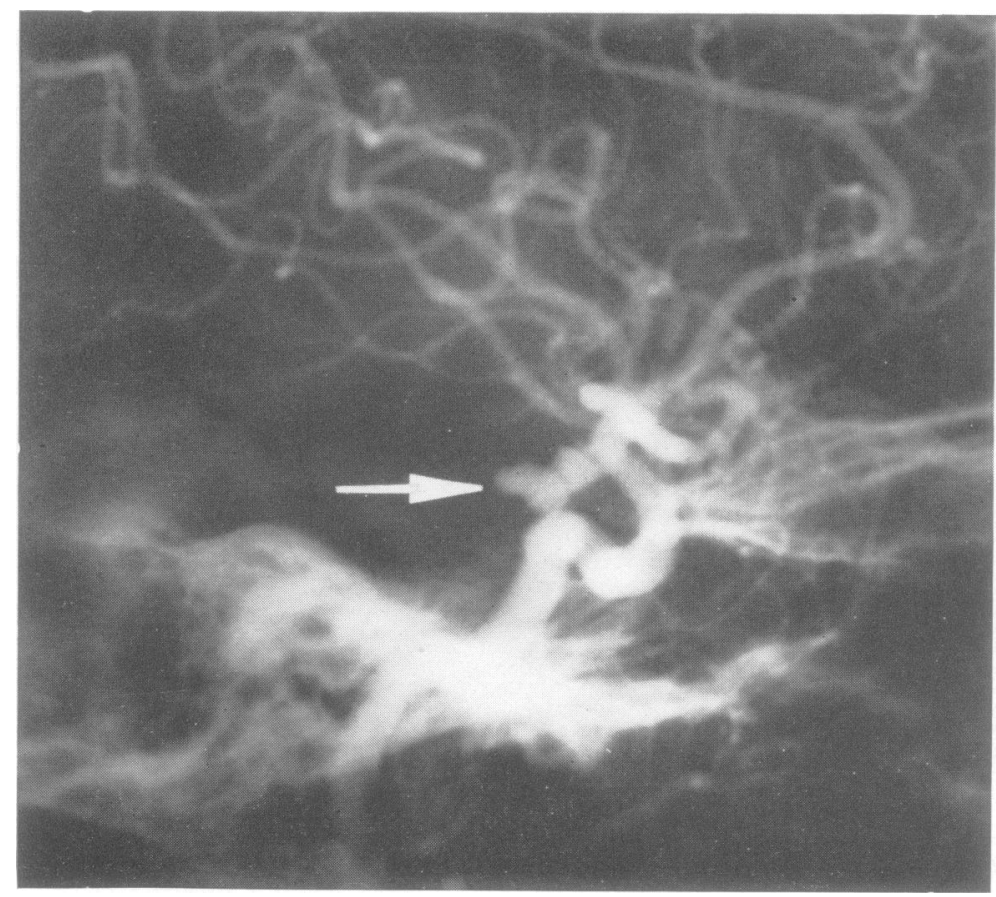

FIG. 5. Right carotid angiogram (lateral view). Multiloculated (3) posterior communicating aneurysm (arrowed), which had caused a third nerve palsy. 
rather than the $44 \%$ of Harris and Udvarhelyi (1957), $54 \%$ of Henderson (1955), or the $56 \%$ of Hamilton and Falconer (1959).

An isolated third nerve palsy can be caused by diabetes mellitus, trauma, or neoplasm (Lincoff and Cogan, 1957; Green et al., 1964; Cheek et al., 1965), but is most commonly due to aneurysms, and among cases presenting to an ophthalmologist this was the cause in $18 \%$ (Rucker, 1966) to $40 \%$ (Balla and Morley, 1967).

Aneurysms other than those of the posterior communicating artery may be involved, because those arising from the infraclinoid carotid artery (Jefferson, 1938) or the basilar artery (Jefferson, 1947; Cogan and Mount, 1963) may also cause an oculomotor paralysis. After a subarachnoid haemorrhage a third nerve palsy may be a false localizing sign if there is uncal herniation (Reid and Cone, 1939) or displacement of the posterior cerebral artery (Sunderland, 1952; Hyland and Barnett, 1954).

Harris and Udvarhelyi (1957) and Raja (1972) did not find any correlation between the radiological measurements of the aneurysm and the clinical picture. Angiography only outlines the patent sac which may bear no similarity to the external shape (Bull, 1969), but in the present series the posterior communicating aneurysm associated with a palsy tended to be multiloculated and larger on the angiogram than those which had not caused one (Figs 4 and 5).

There have been a few descriptions of the effects of carotid ligation on aneurysm induced palsies (Jefferson, 1967; Hamilton and Falconer, 1959; Cantu, 1969; Hepler and Cantu, 1969; Raja, 1972) and brief mention of the results after direct intracranial approach to the aneurysm (Jaeger, 1950; Henderson, 1955; Harris and Udvarhelyi, 1957; Botterell et al., 1962; Johnston and Pratt-Johnson, 1963), but in many of these cases it is impossible to correlate the site of the aneurysm with the type of treatment carried out.

Jefferson (1947) found that the palsy never recovered fully, but Jaeger (1950) stated that, even if the third nerve were seriously withered by pressure, it could still recover completely. Henderson (1955) said that the paralysis had cleared completely in 11 of 23 patients, and Botterell et al. (1962) found that, of 28 patients who had a craniotomy, eight had complete recovery of third nerve function but, of eight who had a carotid ligation, all had residual defects. Cantu (1969) found that recovery of function was better after carotid ligation than after non-surgical treatment of the aneurysm.

The average follow-up time in the present series was seven years but the eye continued to improve for only about two years after operation; only four patients $(22 \%)$ who had a preoperative palsy had recovered completely. No eye returned to normal, and no patient became symptom free if there were a delay of more than 10 days before operation or if signs of recovery had not appeared within a month. This agrees with the findings of Botterell et al. (1962) who said that full recovery occurred only if craniotomy were carried out within 10 days of the onset of the palsy. Hyland and Barnett (1954) found that adherence to the sac and fibrous tissue proliferation led to irreversible damage of the nerve, so it is not surprising that most patients have permanent residual defects which are worse the longer the delay in operation.

The return of third nerve function shows a constant course. The levator palpebrae improves first and in the preoperative palsy group it had recovered fully in 11 patients. The medial rectus muscle recovers well, the inferior rectus less so, and the superior rectus and inferior oblique muscles least well, so that elevation and depression of the globe may remain permanently impaired. However, although regeneration may occur simultaneously to all muscles, the misdirection of nerve fibres to antagonistic groups may give the clinical impression of non-recovery. In addition, there are often persistent defects in the size and reactions of the pupil.

The configuration within the oculomotor nerve of all its constituent fibres is not certain (Walsh and Hoyte, 1969) but the pupilloconstrictor fibres have been found after studies in the cadaver (Sunderland and Hughes, 1946) and in animals (Kerr and Hollowell, 1964) to lie in the medial superior part of the nerve. Which point on the nerve that the aneurysm presses may have a bearing on the final pattern of recovery, and it may be that fibres to the medial rectus and levator muscles are laterally placed away from posterior communicating aneurysms which arise medially.

Recovery of the nerve may be associated with aberrant regeneration which leads to abnormali- 


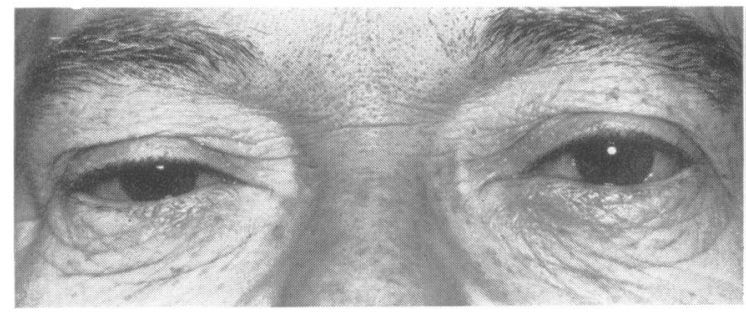

(a)

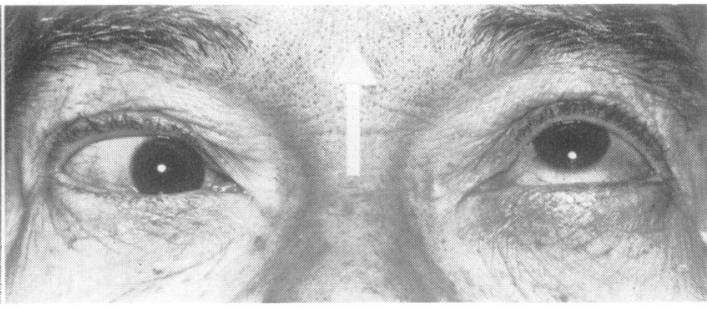

(b)

FIG. 6. Patient 10. (a) Slight ptosis on the right. (b) On attempting to look up the right eye adducts.

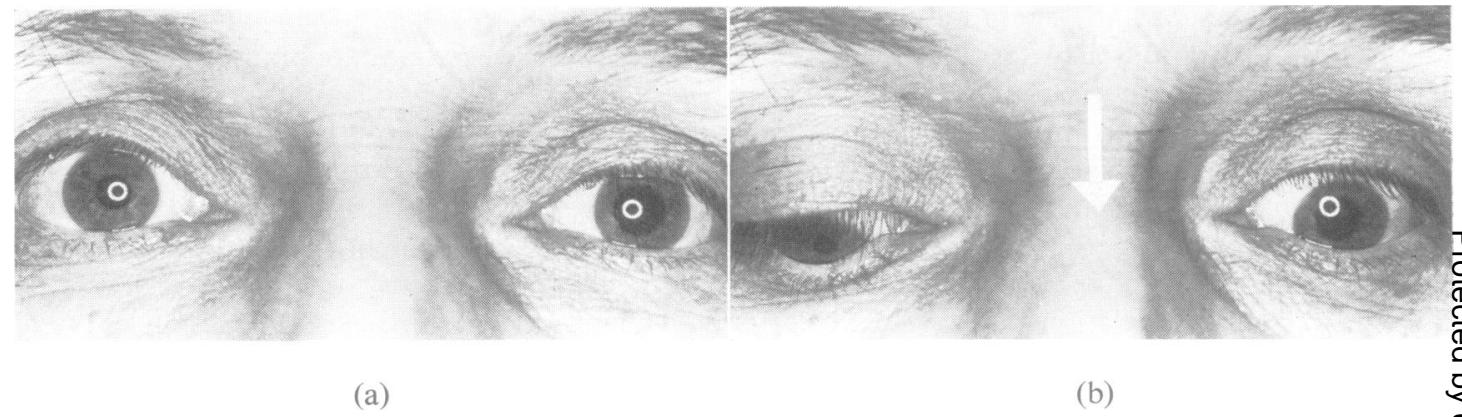

FIG. 7. Patient 11. (a) Slight ptosis on the left and moderately dilated left pupil. (b) The pseudo-Graefe signo On looking down, the left upper eyelid elevates. Note also the deficient depression of the left globe.

ties in movements of the eyelids and globe and in the reactivity of the pupil (Ford and Woodhall, 1938; Bender and Fulton, 1939; Walsh and King, 1942). The upper lid may elevate when the eye is depressed-the pseudo-Graefe sign (Bender, 1936) - and abnormal lid movements may accompany movements of the globe. A mass contraction of the extraocular muscles supplied by the third nerve leads to adduction of the eye instead of elevation (Walsh, 1957) and an Argyll Robertson reaction may occur in which the pupil constricts when the eye moves in the directions controlled by the oculomotor nerve (Ford et al., 1941).

The reported incidence of aberrant regeneration varies greatly. Twenty of 25 patients of Hepler and Cantu (1967), and 16 of 42 in Raja's (1972) series showed the pseudo-Graefe sign, but only two of 40 studied by Botterell et al. (1962) and one of 22 by Henderson (1955) had aberrant regeneration of unspecified type. Two patients of
Hepler and Cantu had an Argyll Robertson pupil.

In the present series, aberrant regeneration was found only if at least four years had elapsed after surgery. Its most common manifestation (nine patients) was adduction of the eye on attempted elevation (Fig. 6). Only three showed the pseudo-Graefe sign (Fig. 7) and none an Argyll Robertson pupil.

\section{CONCLUSIONS}

Posterior communicating aneurysms occur four times more often in women than men and $34 \%$ are associated with an oculomotor paralysis.

The aneurysm causing a palsy is likely to be multiloculated and larger than if not associated with one.

A posterior communicating aneurysm which has caused a palsy may give rise to up to three attacks of severe headache localized to the orbit 
or side of the forehead before the onset of a subarachnoid haemorrhage with coma.

Delay in seeking neurosurgical advice may allow several attacks of pain to occur. This increases the mortality risk and, if a palsy is present, decreases the chance of recovery of oculomotor function.

Third nerve function will not recover completely if the palsy was present for more than 10 days before surgery or if recovery has not started within a few weeks of operation.

Although the eye is usually not troublesome after craniotomy, the majority of patients who had a preoperative palsy have permanently restricted eye movements and pupil abnormalities.

Direct surgery on posterior communicating aneurysms damaged the third nerve in one of seven patients, but in these cases the palsy usually recovered quickly and completely.

Aberrant regeneration of the nerve is likely to occur after craniotomy in all people who had a preoperative palsy, if they have not recovered fully and if followed up for four or more years.

The commonest manifestation of aberrant regeneration is adduction of the eye on attempted elevation.

I wish to thank Mr. C. Langmaid and Mr. R. D. Weeks for permission to study their patients and the Department of Medical Illustration, University Hospital of Wales, for preparing the graphs and photographs. I am very greatly indebted to Miss V. Spooner, Principal of the Orthoptic Department, for undertaking the orthoptic examinations and to Miss K. Davies, statistician, for help with tabulation and analysis of the results.

\section{REFERENCES}

Alpers, B. J., and Schlezinger, N. S. (1949). Aneurysm of the posterior communicating artery. Archives of Ophthalmology, 42, 353-364.

Balla, J. I., and Morley, J. B. (1967). Oculomotor nerve paralysis. Medical Journal of Australia, 1, 755-758.

Beadles, C. F. (1907). Aneurisms of the larger cerebral arteries. Brain, 30, 285-336.

Bender, M. B. (1936). The nerve supply to the orbicularis muscle and the physiology of movements of the upper eyelid. Archives of Ophthalmology, 15, 21-30.

Bender, M. B., and Fulton, J. F. (1939). Factors in functional recovery following section of the oculomotor nerve in monkeys. Journal of Neurology and Psychiatry, 2, 285-292.

Botterell, E. H., Lloyd, L. A., and Hoffman, H. J. (1962). Oculomotor palsy due to supraclinoid internal carotid artery berry aneurysm. American Journal of Ophthalmology, 54, 609-616.

Bull, J. (1969). Massive aneurysms at the base of the brain. Brain, 92, 535-570.

Cantu, R. C. (1969). Oculomotor palsy with posterior communicating artery aneurysm. International Surgery, 52, 144-150.

Cheek, C. W., Simon, K. A., and Gay, A. J. (1965). Acquired cranial nerve lesions affecting the ocular system. American Journal of Ophthalmology, 59, 13-17.

Cogan, D. G., and Mount, H. T. J. (1963). Intracranial aneurysms causing ophthalmoplegia. Archives of Ophthalmology, 70, 757-771.

Dandy, W. E. (1944). Intracranial Arterial Aneurysms, p. 58. Comstock: Ithaca.

Ford, F. R., Walsh, F. B., and King, A. B. (1941). Clinical observations on pupillary phenomena resulting from regeneration of the third nerve with especial reference to the Argyll Robertson pupil. Bulletin of the Johns Hopkins Hospital, 68, 309-318.

Ford, F. R., and Woodhall, B. (1938). Phenomena due to misdirection of regenerating fibers of cranial, spinal and autonomic nerves; clinical observations. Archives of Surgery, 36, 480-496.

France, J. F. (1846). Examples of ptosis with illustrative remarks. Guys Hospital Reports, 4, 37-63.

Green, W. R., Hackett, E. R., and Schlezinger, N. S. (1964). Neuro-ophthalmologic evaluation of oculomotor nerve paralysis. Archives of Ophthalmology, 72, 154-167.

Hamilton, J. G., and Falconer, M. A. (1959). Immediate and late results of surgery in cases of saccular intracranial aneurysms. Journal of Neurosurgery, 16, 514-541.

Harris, P., and Udvarhelyi, G. B. (1957). Aneurysms arising at the internal carotid-posterior communicating artery junction. Journal of Neurosurgery, 14, 180-191.

Henderson, J. W. (1955). Intracranial arterial aneurysms. Transactions of the American Ophthalmological Society, 53, $349-462$.

Hepler, R. S., and Cantu, R. C. (1967). Aneurysms and third nerve palsies. Ocular status of survivors. Archives of Ophthalmology, 77, 604-608.

Hutchinson, J. (1875). Aneurism of the internal carotid within the skull diagnosed eleven years before the patient's death. Spontaneous cure. Transactions of the Clinical Socicty of London, 8, 127-131.

Hyland, H. H., and Barnett, H. J. M. (1954). The pathogenesis of cranial nerve palsies associated with intracranial aneurysms. Proceedings of the Royal Society of Medicine, 47, 141-146.

Jaeger, R. (1950). Aneurysm of the intracranial carotid artery. Journal of the American Medical Association, 142, 304-310.

Jefferson, G. (1938). On the saccular aneurysms of the internal carotid artery in the cavernous sinus. British Journal of Surgery, 26, 267-302.

Jefferson, G. (1947). Isolated oculomotor palsy caused by intracranial aneurysm. Proceedings of the Royal Society of Medicine, 40, 419-432.

Johnston, A. C., and Pratt-Johnson, J. A. (1963). The ocular sequelae of third cranial nerve palsy. Canadian Medical Association Journal, 89, 871-873.

Kerr, F. W. L., and Hollowell, O. W. (1964). Location of pupillomotor and accommodation fibres in the oculomotor nerve: experimental observations on paralytic mydriasis. Journal of Neurology, Neurosurgery, and Psychiatry, 27, 473-481.

Lincoff, H. A., and Cogan, D. G. (1957). Unilateral headache and oculomotor paralysis not caused by aneurysm. Archives of Ophthalmology, 57, 181-189. 
Madow, L., and Alpers, B. J. (1953). Aneurysm of the posterior communicating artery. Archives of Neurology and Psychiatry, 70, 722-732.

Paterson, A. (1968). Direct surgery in the treatment of posterior communicating aneurysms. Lancet, 2, 808-811.

Raja, I. A. (1972). Aneurysm-induced third nerve palsy. Journal of Neurosurgery, 36, 548-551.

Reid, W. L., and Cone, W. V. (1939). The mechanism of fixed dilatation of the pupil. Journal of the American Medical Association, 112, 2030-2034.

Rucker, C. W. (1966). The causes of paralysis of the third, fourth and sixth cranial nerves. American Journal of Ophthalmology, 61, 1293-1298.

Sunderland, S. (1952). Mechanism responsible for changes in the pupil unaccompanied by disturbances of extra-ocular muscle function. British Journal of Ophthalmology, 36, 638644.

Sunderland, S., Hughes, E. S. R. (1946). The pupilloconstrictor pathway and the nerves to the ocular muscles in man. Brain, 69, 300-309.

Symonds, C. P. (1923). Contributions to the clinical study of intracranial aneurysms. Guys Hospital Reports, 73, 139158.

Walsh, F. B. (1957). Third nerve regeneration. A clinical evaluation. British Journal of Ophthalmology, 41, 577-598.

Walsh, F. B., and Hoyte, W. F. (1969). Clinical Neuroophthalmology, 3rd edn., vol. 1, p. 201. Williams and Wilkins: Baltimore.

Walsh, F. B., and King, A. B. (1942). Ocular signs of intracranial saccular aneurysms. Archives of Ophthalmology, 27, 1-33. 